\title{
Nurses' Awareness toward Risk Factors of Breast Cancer in Kirkuk City
} Hospitals

Burhan Qader Saadoon; Department of Nursing, College of Nursing, Sulaimani University, Sulamani, Iraq. (Correspondence: borhanqader@gmail.com )

Salih Ahmed Abdulla; Department of Nursing, College of Nursing, Hawler Medical University, Erbil, Iraq.

\section{ABSTRACT}

Background and objectives: In women worldwide, breast cancer is the most common cancer. It is one of the leading causes of cancer death in women, accounting for $15 \%$ of all cancer deaths in the female population. In most countries, breast cancer incidence rates are higher than they have ever been at an early age. This study aimed to identify the level of nurses' awareness towards risk factors of breast cancer.

Methods: A cross-sectional study was carried out among 341 nurses from different departments in three Kirkuk city hospitals (Azadi Teaching Hospital, Kirkuk General Hospital, and Pediatric Hospital) from 25 February to 25 June 2021. A non-probability/convenient sampling technique was utilized to collect data. A socio-demographic characteristics data form and awareness of breast cancer risk factors form were used to collect data through face-to-face interviews. Data were analyzed using Statistical Package for the Social Sciences, version 21 , presenting descriptive and inferential statistics comprising frequency, percentage and chi-square test.

Results: Out of the 341 nurses, $44.9 \%$ were from Azadi Teaching Hospital, while more than one-third (38.1\%) were from Kirkuk General Hospital, and $17 \%$ were from Pediatric Hospital. Most of the nurses, 38.4\%, were between the ages of 21 and 25, 64.8\% were female, and $66.9 \%$ were married. About $36.1 \%$ of nurses report acceptable level of awareness and $5.9 \%$ report being with good level of awareness about risk factors associated with breast cancer.

Conclusion: The awareness level of breast cancer risk factors among nurses working in Kirkuk city hospitals was generally high. Younger age was associated with higher level of awareness of risk factors. Regarding to the gender was highly significant differences between the nurses' awareness of breast cancer risk factors.

Keywords: Breast cancer, Risk factors, Nurses, Awareness.

Received: 14/09/2021

Accepted: $18 / 11 / 2021$

Published: 30/11/2021

\section{INTRODUCTION}

Breast cancer, the proliferation of cells in breast tissue, is a deadly malignancy worldwide. This disorder is characterized by lumps in the breast, persistent pain in the breast or armpit, dimpling of the skin, shifting the location of the nipples, rashes on the nipple and swelling under the armpit. This condition is not limited to women only. In both developed and developing countries, it is the most common form of cancer diagnosed in women around the world, with more than one million cases 
occurring annually [1]. Breast cancer development can be categorized by genetic, lifestyle and environmental factors. Genetic factors include age, race, familial/personal history of breast cancer, early menstruation (before age 12), late menstruation (after age 51), genetic influences, and dense breast tissue. Lifestyle and environmental factors include parity, contraceptive use, hormone replacement therapy after menopause, breastfeeding, tobacco use, obesity or overweight, and poor diet and exercise [2]. In most countries, breast cancer incidence rates are higher than they have ever been at an early age, and these results are generally highest where historically low rates have been reported [3]. The first and most common symptom of breast cancer is a painless lump or thickening in the breast. Breast pain or heaviness, changes in breast size and form, swelling, and nipple defects, such as spontaneous discharge (especially if bloody), erosion, or retraction, are other signs and symptoms [4]. On mammograms, the first symptoms of breast cancer are typically seen, even before lumps can be felt [5]. Breast cancer is a big health issue for women and society. Community and general nurses are the primary teams of health care professionals who are easily approachable and can serve as the future health educator. The preventive services provided by nurses in the form of health evaluation, screening, and therapy can be incorporated into systematic health promotion and safety programs at the community level. The optimal initial step for the community health nurse is to evaluate women's history awareness and attitudes prior to the planning and involvement in conducting breast cancer teaching programs [6]. Breast cancer compensates one-tenth of all newly diagnosed cancer cases worldwide. Five percent of new breast cancer diagnoses occur in women less than 40 years of age. This may contribute to higher rates of mortality from breast cancer in younger women. The 5 -year relative survival rate of young women who are 40 years of age or younger is significantly lower compared to women who are 40 and older. Screening for early detection and having awareness about risk reduction is important for young people [7]. The presence of a lump in the breast that progressively enlarges over time is usually an early sign. If these symptoms are identified, it is better to obtain immediate medical advice [8]. The purpose of this study is to evaluate nurse's level of awareness about breast cancer risk factors and explain how that may influence their ability to provide information and care for their patients.

\section{METHODS}

A cross-sectional study was carried out among 341 nurses at different departments in three Kirkuk city hospitals from 25 February to 25 June 2021. A nonprobability/convenient sampling technique was utilized to collect data. The inclusion criteria were male and female nurses working morning, evening, and night shifts who agree to participate in this study. Exclusion criteria are those who refused participation or absent during the period of data collection, and nurses who work in managerial role. The sample size was determined by $\mathrm{K}=$ components ( $\mathrm{K}$-items or test lets). $\sigma 2 X=$ The variance of the observed total test scores. $\sigma 2 \mathrm{Yi}=$ The variance of component $i$ for the current sample of persons [9] Reliability was determined using the Cronbach's alpha (0.82) values. In order to collect the proper information of the study, the questionnaire was designed and constructed by the researcher to measure the variables underlying the present study. The researcher prepared a questionnaire for collecting data based on the review literature. The questionnaire 
consists of two parts: 1) socio demographic characteristics section, and 2) observation checklist with information related to level awareness about breast cancer risk factors, each questionnaire item regarding level of awareness had 3 responses: Yes rated as (1), No is rated as (2) and, I don't know rated as (3). The level of awareness is scored by calculating the lowest total of the incorrect answers "Yes" or "No". A value of "015.5 " indicated poor level of awareness, a value of "16-20" indicated an acceptable level, a value of "21-25" indicated an intermediate level, and a value of "26-31" indicated a good level. Face-to-face interviews of 30 minutes was also used to collect data. All participants were informed that the information will be kept confidential and use for scientific purposes only. The questionnaire was verified by a panel of experts who have extensive experience from different specialties. Based on their comments, the questionnaire was corrected and modified for appropriate data collection. Before conducting interviews, the researchers explained the purpose to all participants and acquired their oral consent, with ethical permission from the University of Sulaimani/College of Medicine and its ethics committee the No: 112 and date of the approval $25 / 5 / 2021$. The hospital's director gave approval prior to data collection, and the unit's nurse in charge were informed. A pilot study was carried out on 30 nurses through the period from 16-24 February in 2021. The pilot study was beneficial to determine the reliability of the study instrument. The result of the pilot study revealed that the items of the questionnaire were clear and understandable to the participants and required some modification in the "socio-demographic characteristics" section. Each questionnaire took approximately 30 minutes to complete. The data was summarized and analyzed through using the application statistical package for social science (SPSS) version 21 and the following statistical test were used in data analysis: descriptive statistical data analysis:

This approach applied through the measurement of the following:
a. Frequencies $(f): n$. of samples
b. Percentages (\%):
c. Means:
d. Standard Deviation (SD): SD

Inferential statistical data analysis: For the abbreviations of the Comparative Significance (CS), we used the following:

NS: Not significant at $p$. value $\geq 0.05$

S: significant at $p$. value $<0.05$

HS: Highly significant at $p$. value $<0.01$

Analysis of Variance (ANOVA) test: A parametric statistical test used to compare the differences between the means of two or more groups by comparing the variability between groups and within groups. This test was used to determine the differences in the means of nurses' awareness level about the risk factors for breast cancer to different subject variables.

\section{RESULTS}

Table 1 shows the socio-demographic characteristics of the sample. Nearly half of the sample (44.9\%) were from Azadi Teaching Hospital, more than a third (38.1\%) were from Kirkuk General Hospital, and about $17 \%$ were from Pediatric Hospital. $38.4 \%$ of the sample were aged 21-25 years old, $64.8 \%$ were female, and $66.9 \%$ were married. Less than half $(41 \%)$ of the population were institute graduates. About $18.8 \%$ of the population worked in medical wards, and $14.7 \%$ worked in surgical wards. $47.8 \%$ of the population had $1-5$ years of experience. $94.4 \%$ of the population reported they had not had breast cancer, and $61.3 \%$ reported not caring for breast cancer patients. Finally, based on participation in the trainings, the nonparticipated sample made the majority 
percentage (65.1\%) of whole sample. Table 2 shows the levels of awareness about breast cancer risk factors for the study sample.
As shown in this table, most of the study sample (36.1\%) have an acceptable level of awareness about breast cancer risk factors.

Table 1: Distribution of the Socio-demographical data characteristics of the Study Sample (No.: 341).

\begin{tabular}{|c|c|c|c|}
\hline The Socio-demographical Characteristics & Subgroups & $f$. & $(\%)$ \\
\hline \multirow{3}{*}{ Hospital Name } & Azadi Teaching Hospital & 153 & (44.9) \\
\hline & Kirkuk General Hospital & 130 & $(38.1)$ \\
\hline & Pediatric Hospital & 58 & $(17)$ \\
\hline \multirow{7}{*}{ Age Groups/Years } & $21-25$ & 131 & $(38.4)$ \\
\hline & $26-30$ & 101 & $(29.6)$ \\
\hline & $31-35$ & 21 & $(6.2)$ \\
\hline & $36-40$ & 29 & (8.5) \\
\hline & $41-45$ & 30 & $(8.8)$ \\
\hline & $46-50$ & 16 & (4.7) \\
\hline & More than 50 & 13 & (3.8) \\
\hline \multirow{3}{*}{ Gender } & Male & 120 & $(35.2)$ \\
\hline & Female & 221 & $(64.8)$ \\
\hline & Single & 111 & $(32.5)$ \\
\hline \multirow{4}{*}{ Marital Status } & Married & 228 & (66.9) \\
\hline & Separated & 1 & $(0.3)$ \\
\hline & Divorced & 1 & $(0.3)$ \\
\hline & Preparatory Graduated & 92 & (27) \\
\hline \multirow{2}{*}{ Education Level } & Institute Graduated & 140 & (41) \\
\hline & College Graduated & 105 & $(30.8)$ \\
\hline \multirow{13}{*}{ Departments } & Post-graduate & 4 & $(1.2)$ \\
\hline & Surgical Ward & 50 & $(14.7)$ \\
\hline & Medical Ward & 64 & $(18.8)$ \\
\hline & Pediatric Ward & 15 & $(4.4)$ \\
\hline & $\begin{array}{l}\text { Gynecology \& Obstetric } \\
\text { Ward }\end{array}$ & 34 & (10) \\
\hline & Consultant Clinics & 26 & (7.6) \\
\hline & Emergency Room & 33 & (9.7) \\
\hline & Operation Theater & 34 & (10) \\
\hline & $\mathrm{CCU}$ & 24 & $(7)$ \\
\hline & $\mathrm{RCU}$ & 19 & (5.6) \\
\hline & Premature Unit & 27 & (7.9) \\
\hline & Mammography Unit & 5 & (1.5) \\
\hline & $\begin{array}{l}\text { Dialysis Unit (Artificial } \\
\text { Kidney) }\end{array}$ & 10 & (2.9) \\
\hline \multirow[t]{2}{*}{ The Socio-demographical Characteristics } & Subgroups & $f$. & $(\%)$ \\
\hline & Less than 1 Year & 47 & $(13.8)$ \\
\hline \multirow{7}{*}{ Years of experience } & $1-5$ & 163 & $(47.8)$ \\
\hline & $6-10$ & 54 & $(15.8)$ \\
\hline & $11-15$ & 25 & $(7.3)$ \\
\hline & $16-20$ & 21 & $(6.2)$ \\
\hline & $21-25$ & 15 & (4.4) \\
\hline & $26-30$ & 10 & (2.9) \\
\hline & 31 Years + more & 6 & (1.8) \\
\hline \multirow{2}{*}{ Suffered from BC } & Yes & 19 & $(5.6)$ \\
\hline & No & 322 & $(94.4)$ \\
\hline \multirow{2}{*}{ Cared of BC Patients } & Yes & 132 & $(38.7)$ \\
\hline & No & 209 & $(61.3)$ \\
\hline \multirow{2}{*}{ Participating in Trainings } & Non-Participated & 222 & $(65.1)$ \\
\hline & Yes - One Training & 119 & (34.9) \\
\hline
\end{tabular}


Table 2: Distribution of the levels of the awareness about breast cancer risk factors for the study sample (No.: 341)

\begin{tabular}{ccccc}
\hline Awareness levels about breast cancer risk factors & $\boldsymbol{f}$ & \% & Mean & S.D. \\
\hline Poor Level & 106 & 31 & & \\
Acceptable Level & 123 & 36.1 & $\mathbf{2 0 8}$ & $\mathbf{0 . 9 0 1}$ \\
Intermediate Level & 92 & 27 & & \\
Good Level & 20 & 5.9 & & \\
Total & $\mathbf{3 4 1}$ & $\mathbf{1 0 0}$ & \\
\hline
\end{tabular}

Table 3 shows no significant differences between the study samples regarding their age groups ( $p$-value $=0.978$ )
Table 4 shows highly significant differences between the study sample responses regarding gender ( $p$-value $<0.001)$.

Table 3: Comparisons the levels of the awareness about breast cancer risk factors regarding to the age group of the study sample by One-Way ANOVA test.

\begin{tabular}{|c|c|c|c|c|c|c|c|}
\hline Awareness & $\begin{array}{c}\text { Age } \\
\text { Groups }\end{array}$ & $f$ & $\%$ & Mean $\pm S D$ & F. value & \multicolumn{2}{|c|}{ Sig. value } \\
\hline \multirow{8}{*}{$\begin{array}{l}\text { Awareness levels about breast } \\
\text { cancer risk factors }\end{array}$} & $21-25 \mathrm{Y}$. & 131 & 38.42 & $2.11 \pm 0.897$ & \multirow{8}{*}{0.195} & \multirow{8}{*}{0.978} & \multirow{8}{*}{ N.S. } \\
\hline & 26-30Y. & 101 & 29.62 & $2.10 \pm 0.911$ & & & \\
\hline & 31-35 Y. & 21 & 6.16 & $2.05 \pm 1.024$ & & & \\
\hline & $36-40 \mathrm{Y}$. & 29 & 8.50 & $1.97 \pm 0.865$ & & & \\
\hline & 41-45 Y. & 30 & 8.8 & $2.10 \pm 0.960$ & & & \\
\hline & 46-50 Y. & 16 & 4.69 & $2.00 \pm 0.894$ & & & \\
\hline & $\begin{array}{c}\text { More than } \\
50 \mathrm{Y} .\end{array}$ & 13 & 3.81 & $1.92 \pm 0.760$ & & & \\
\hline & Total & 341 & 100 & $2.08 \pm 0.901$ & & & \\
\hline
\end{tabular}

F. value: ANOVA test value.

Table 4: Comparisons the levels of the awareness about breast cancer risk factors regarding to the sex of the study sample by Chi-Square test.

\begin{tabular}{|c|c|c|c|c|c|c|c|}
\hline Awareness & Sex & $f$. & $\%$ & Mean \pm SD & F. value & Sig. & lue \\
\hline \multirow[t]{2}{*}{$\begin{array}{l}\text { Awareness levels about breast } \\
\text { cancer risk factors }\end{array}$} & Male & 120 & 35.19 & $2.07 \pm 0.914$ & \multirow[t]{2}{*}{72.243} & \multirow[t]{2}{*}{0.001} & \multirow[t]{2}{*}{ H.S. } \\
\hline & Female & 221 & 64.81 & $2.08 \pm 0.896$ & & & \\
\hline
\end{tabular}

F. value: Chi-Square test. 
Table 5 shows a significant difference regarding marital status at ( $p$-value 0.041$)$. between the study sample responses

Table 5: Comparisons the levels of the awareness about breast cancer risk factors regarding to the marital status of the study sample by One-Way ANOVA test.

\begin{tabular}{lccccccc}
\hline \multicolumn{1}{c}{ Awareness } & Marital Status & $f$. & $\%$ & Mean \pm SD & F. value & Sig. value \\
\hline & Single & 111 & 32.6 & $2.26 \pm 0.922$ & & & \\
Awareness levels & Married & 228 & 66.8 & $1.98 \pm 0.880$ & & & \\
about breast cancer & Separated & 1 & 0.3 & $2.00 \pm .000$ & $\mathbf{2 . 7 7 9}$ & $\mathbf{0 . 0 4 1}$ & S. \\
risk factors & Divorced & 1 & 0.3 & $3.00 \pm .000$ & & & \\
& Total & $\mathbf{3 4 1}$ & $\mathbf{1 0 0}$ & $\mathbf{2 . 0 8} \pm 0.901$ & & & \\
& & & & & &
\end{tabular}

\section{DISCUSSION}

A high percentage of the sample (38.4\%) were between the ages of 21-25, and those over 50 contributed to the lower percentage (3.8\%). This result agrees with the result of the study [10] in their research "Assessment of Knowledge of Breast Cancer and Screening Methods among Nurses in University Hospitals in Addis Ababa, Ethiopia, 2011". This might be explained because of the need for new staff nurses to work at all hospital departments, and these ages were capable of bearing and tolerating the burdens of working with patients. The majority of sample were female (643.8\%) which is in agreement with the result of a study with the higher percentage of the population (89\%) were female [11]. The majority of sample in the study were married $(66.9 \%)$, a finding which is in disagreement with the result of the study [12] which mentions that most of the nurses $(51.2 \%)$ are single. Which is in agreement with the study done in Jordanian nurses [13] which mentions that most of the nurses $(51.8 \%)$ are married. Concerning graduation level, most of the sample study (41\%) had a degree in nursing, and $1.2 \%$ had higher studies of nursing science degree. A higher proportion of the sample (18.88\%) worked in medical wards, and $14.7 \%$ worked in surgical wards. This finding was similar with the finding of another study [11]. There are separate wards for men and women in the medicine and surgery departments in Kirkuk City Hospitals. Regarding the years of experience in departments, it has been noted that $47.8 \%$ of nurses had 1 to 5 years, while $1.8 \%$ of nurses had more than 31 years of experience. This result in agreement with the result of the study among nurses in University Hospitals in Addis Ababa, Ethiopia, 2011 which reported $61.1 \%$ of nurses had below 5 years of experience, while 1.5 of nurses had more than 31 years of experience [10]. $94.4 \%$ of the sample reported they had not had breast cancer ad, $61.3 \%$ reported not caring for any breast cancer patients. This finding was similar with the finding of another study which reported 99.3\% of the sample had not had breast cancer and, $54.1 \%$ not caring for any breast cancer patients [11]. Training courses are necessary to improve nurses' awareness of breast cancer in all hospital departments. Based on participation in the 
trainings, the non-participated sample made the majority proportion $(65.1 \%)$ of whole sample, and the participated sample $(34.9 \%)$ made the lowest percentage of the sample. Continuing education is the best way to update the nurses' awareness of breast cancer regarding risk factors. Concerning awareness levels about breast cancer risk factors items have a mean score of 2.08 and a standard deviation of .901. This indicates that total average of breast cancer risk factors events that occur in the workplace perceived by nursing staff in many hospital departments. Nurses in Kirkuk City Hospital had poor level of awareness (31\%) which is in agreement with the study results among nurses in teaching hospitals of Karachi, Pakistan reporting 25\% of nurses had poor level of awareness of breast cancer risk factors [14]. The overall level of awareness towards this breast cancer was similar among male and female nurses, single and married nurses, younger and older nurses, and among nurses with different educational levels. The level of awareness was also not influenced by years of experience, previous history of breast cancer, or a history of caring for a breast cancer patient. The results of present study disagree with the study among nurses and midwives in Mulago Hospital which reports $91.11 \%$ of the sample had poor level of awareness of breast cancer risk factors [11]. This could be explained by the lack training programs and sensitization workshops for the health care professionals in the hospital. The finding indicated that there were no statistical significant differences between the study samples regarding their age groups ( $p$-value=0.978). The outcome of the study agrees with the result of a study among a cohort of nurses in Iran that showed there were no statistically significant statistically differences in level of awareness about breast cancer risk factors due to age groups as indicated by $p$-value $=0.294$ ) [15].

\section{CONCLUSION}

The level of awareness of breast cancer risk factors was generally high among nurses working in Kirkuk City hospitals. The lower the age group the higher awareness on breast cancer risk factors. The study findings report highly significant differences between the nurses' awareness of breast cancer risk factors by gender.

\section{RECOMMENDATION}

Based on the findings of this study, the promotion of future health policies, such as mandatory continuing education is highly recommended to improve awareness levels of breast cancer risk factors among nurses. There is a need for the Ministry of Health, hospital management, training institutions to improve breast cancer content in the nursing curriculum. As the implementation of the revised curriculum may take some time, workplace training courses for the nurses can be introduced relatively earlier. Nurses are encouraged to disseminate this knowledge effectively and appropriately within the general population.

\section{COMPETING INTERESTS}

The author declares no competing interests. 


\section{REFERENCES}

[1] MAGGLE, A. KNOWLEDGE, ATTITUDES AND PRACTICES OF WOMEN ON BREAST CANCER AND BREAST SELF EXAMINATION IN KISAASI, KAWEMPE DIVISION (Doctoral dissertation, MAKERERE UNIVERSITY). 2015.

[2] Badr, L. K., Bourdeanu, L., Alatrash, M., \& Bekarian, G. Breast cancer risk factors: a cross-cultural comparison between the West and the East. Asian Pacific Journal of Cancer Prevention: APJCP, 2018; 19(8), 2109.

[3] El-Nasr, E. M. S. Breast Cancer risk factors and screening practices Among Women Attending Family Health Centers in Cairo Governorate. Journal of Nursing and Health Science, (IOSR-JNHS, 6(3), 12-23, 2017.

[4] Hamad, K. J., Khalil, H. M., \& Awlla, H. A. Knowledge of breast cancer risk factors and practice of breast self- examination among female students of soran technical institute. Polytechnic Journal, 2018, 8(3), 203-218.

[5] Agbonifoh, J. A. Breast Self -Examination Practice among Female Students of Tertiary Institutions. Journal of Education and Practice, 2016, 7(12), 11-18.

[6] Al-Rikabi, A., \& Husain, S. Increasing prevalence of breast cancer among Saudi patients attending a tertiary referral hospital: a retrospective epidemiologic study. Croatian Medical journal, 2012; 53 (3), 239.

[7] Ansah, M. B. Female students' knowledge, beliefs, attitude and practice of breast selfexamination in a university in the Western Cape (Doctoral dissertation, Cape Peninsula University of Technology). 2015.

[8] Chowdhury, S., \& Sultana, S. Awareness on breast cancer among the women of reproductive age,2011.

[9] Yount R., Correlation Coefficient, chapter 22 Reliability, 4th edition, 2006, pp:2-7

[10] Lemlem, S. B., Sinishaw, W., Hailu, M., Abebe, M., \& Aregay, A. Assessment of knowledge of breast cancer and screening methods among nurses in university hospitals in Addis Ababa, Ethiopia, 2011. International Scholarly Research Notices 2013, 2013.
[11] Ekong, O. Awareness of breast cancer risk factors and early detection measures and associated factors among nurses and midwives at mulago hospital. Unpublished masters' thesis). Makerere University, Kampala, Uganda. 2009.

[12] Andegiorgish, A. K., Kidane, E. A., \& Gebrezgi, M. T. Knowledge, attitude, and practice of breast Cancer among nurses in hospitals in Asmara, Eritrea. BMC nursing, 17(1), 1 -7, 2018

[13] Amasha, H. A. R. Breast self-examination and risk factors of breast cancer: Awareness of Jordanian nurses. Health Science Journal, 2013: 7(3), 303.

[14] Ahmed, F., Mahmud, S., Hatcher, J., \& Khan, S. M. Breast cancer risk factor knowledge among nurses in teaching hospitals of Karachi, Pakistan: a cross-sectional study. $B M C$ nursing, 2006, 5(1), 1-7.

[15] Ghahremanfard, F., Ghorbani, R., \& Hemmati, S. Knowledge of breast cancer risk factors among a cohort of nurses in Iran. Iranian Journal of Blood and Cancer, 2014, 183-187. 